\title{
Determination of Environmental Tobacco Smoke from a Second-Generation Electrically Heated Cigarette Smoking System and Conventional Cigarettes*
}

\author{
by \\ Jan Oey, Raymond W. Lau, and Hans J. Roethig \\ Philip Morris USA Inc Research Center, 4201 Commerce Road, Richmond VA 23234, USA
}

\section{SUMMARY}

This substudy of a randomized, controlled, forced switching, open-label, parallel-group clinical study in a total of 100 healthy adult male and female smokers compared environmental tobacco smoke (ETS) produced from smoking a second generation electrically heated cigarette smoking system (EHCSS), two conventional cigarettes, and no-smoking. Concentrations of air constituents including respirable suspended particulate matter (RSP), carbon monoxide (CO), and total volatile organic compounds (TVOCs) and ETS markers including solanesolrelated particulate matter (Sol-PM), ultraviolet absorbing particulate matter(UVPM), fluorescing particulate matter (FPM), nicotine and 3-ethenylpyridine (3-EP) were measured in a ventilated, furnished conference room over a period of 2 hours on separate occasions. Except for TVOCs, concentrations of air constituents and ETS markers were reduced by $40 \%$ to more than $90 \%$ when adult smokers were smoking the EHCSS as compared to smoking conventional cigarettes. $\mathrm{CO}$ and most ETS marker concentrations were in the same range as nosmoking. [Beitr. Tabakforsch. Int. 23 (2008) 1-7]

\section{ZUSAMMENFASSUNG}

In dieser Subuntersuchung einer randomisierten, kontrollierten, "forced switching', offenen, klinischen Studie mit Parallelgruppen bestehend aus 100 gesunden männlichen und weiblichen Rauchern wurde Tabakrauch in der Raumluft(ETS), der von einem elektrisch geheizten Zigarettenrauchsystems (EHCSS) zweiter Generation generiert wurde, ETS von konventionellen Zigaretten und Raumluft miteinander verglichen. Die Konzentrationen der Luftbestandteile, und zwar einatembare, fein verteilte Partikel (RSP), Kohlenmonoxid (CO) und alle flüchtigen organische Verbindungen (TVOCs) sowie ETS Marker einschließlich Solanesol-basierter Partikelmasse (Sol-PM), ultraviolett-absorbierender Partikelmasse (UVPM), fluoreszierende Partikelmasse (FPM), Nikotin und 3-Ethenylpyridin (3-EP) wurden in einem ventilierten, eingerichteten Konferenzraum während zwei Stunden zu verschiedenen Gelegenheiten gemessen. Mit Ausnahme der TVOCs waren die Konzentrationen der untersuchten Luftbestandteile und der ETS-Marker um 40\% bis zu mehr als $90 \%$ verringert, wenn die Raucher EHCSS im Vergleich zu konventionellen Zigaretten rauchten. $\mathrm{CO}$ und die meisten ETS Marker-Konzentrationen waren mit der Raumluft ohne Tabakrauch zu vergleichen. [Beitr. Tabakforsch. Int. 23 (2008) 1-7]

\section{RESUME}

Dans cet examen d'une étude clinique randomisée et contrôlée, avec un changement du type de cigarette forcé exécutée en parallèle avec cent fumeurs et fumeuses adultes, la fumée de tabac environnementale (ETS) dégagée par le fumage d'une cigarette chauffée électriquement de deuxième génération (EHCSS), de deux cigarettes conventionnelles et la situation du "non fumage" ont été comparées. Les échantillons d'air ont été analysés pour leur contenu en matière particulaire respirable en suspension (RSP), monoxyde de carbone (CO), composés totaux organiques volatils (TVOCs) et marqueurs de l'ETS, y compris la matière particulaire liée au solanésol (Sol-PM), la matière particulaire absorbant les UV (UVPM), la 
matière particulaire fluorescente (FPM), la nicotine et la 3-éthényl pyridine (3-EP). Les analyses ont été effectuées dans une salle de conférence ventilée et meublée pour une période de deux heures à plusieurs occasions. Sauf pour les TVOCs, les teneurs en composants d'air analysés et les marqueurs de l'ETS sont réduits de $40 \%$ à $90 \%$ si les fumeurs adultes fument les EHCSS en comparaison avec le fumage de cigarettes conventionnelles. Les teneurs en CO et la plupart des marqueurs de l'ETS sont comparables au "non fumage". [Beitr. Tabakforsch. Int. 23 (2008) 1-7]

\section{INTRODUCTION}

Environmental tobacco smoke (ETS) is a complex mixture, consisting of sidestream smoke and exhaled mainstream smoke after deposition of a major fraction of mainstream smoke in the respiratory tract, diluted with room air and aged (1). ETS from conventional cigarettes is comprised of approximately $57-85 \%$ aged and diluted sidestream cigarette smoke and $15-43 \%$ aged and diluted exhaled mainstream cigarette smoke (2). Public health officials have concluded that ETS from cigarettes causes disease, including lung cancer and heart disease, in nonsmoking adults (3). In the recent updated IARC Monograph on Tobacco Smoke and Involuntary Smoking (1) it was concluded that "Involuntary smoking (exposure to secondhand or 'environmental' tobacco smoke) is carcinogenic to humans (Group 1)".

The Electrically Heated Cigarette Smoking System (EHCSS) $(4,5,6)$, consists of an electrically heated cigarette and utilizes temperature controlled combustion during puffing of the cigarette. There is no continuous burning of tobacco like in conventional cigarettes as the electrically heated blades of the EHCSS are only activated for a period of 2 seconds by a flow sensor during puffing. Due to the controlled combustion in a micro-processor controlled lighter during the smoking process, no sidestream smoke is generated by the EHCSS, and ETS is limited to exhaled mainstream smoke. A prior study demonstrated when a first-generation EHCSS was smoked that levels of carbon monoxide (CO), total volatile organic compounds (TVOCs), and particulate matter were comparable to levels observed when there was no smoking in the room (7). In another study with three adult smokers smoking a first generation EHCSS it was shown that most of the measured ETS markers were lower compared to ETS from a conventional lit-end cigarette (8).

Extensive research has been done on the measurement of ETS, however, there are no standardized criteria for the development of experimental atmospheres that represent ETS (reviewed in 1, 3). We have developed conditions and methods for comparing ETS produced under controlled human smoking conditions (7). The conditions were designed to simulate conditions that might be encountered in real-life situations, such as ventilated furnished rooms. Recently, a protocol was developed by JENKINS et al. (9) for the generation and determination of particles from indoor aerosols including simulated ETS. In this protocol real-time monitoring instrumentation based on nephelometry, such as DustTrak ${ }^{\circledR}$, was used to measure respirable suspended particulate matter (RSP).
Furthermore, gravimetric RSP sampling was used to collect particulate-phase and vapor-phase species were collected in a fashion similar to that described by OGDEN et al. (10). Particulate-phase species determined were gravimetric RSP, solanesol-related particulate matter (SolPM), ultraviolet absorbing particulate matter (UVPM) and fluorescing particulate matter (FPM) (9).

The purpose of this study was to determine in real time ETS produced by adult smokers smoking the second generation EHCSS or conventional cigarettes in a normal indoor environment utilizing the method as described by JENKINS et al. (11). The measurement was extended to include ETS vapor-phase markers, including nicotine [unlike in mainstream smoke where nicotine mostly remains in the particulate phase, most of the nicotine evaporates from the particulate matter into the vapor phase as it is diluted to ETS concentrations (12)] and 3ethenylpyridine (3-EP). In addition, a commercial multigas monitor was used to monitor real-time gases in ETS, i.e., $\mathrm{CO}$ and TVOCs.

\section{METHODS}

\section{Study design}

This was a substudy of a randomized, controlled, forced switching open-label, parallel-group clinical study in a total of 100 adult healthy male and female smokers investigating levels of biomarkers of exposure to cigarette smoke constituents from the second generation EHCSS and two conventional cigarettes as described previously (13). The study protocol was reviewed and approved by the Institutional Review Board of the investigational site (MDS Pharma Services, Lincoln, NE). After giving informed consent and passing screening, adult smokers of conventional cigarettes [11 mg 'tar', Federal Trade Commission (FTC), CC1] were confined at the study site. Subjects continued to smoke CC1 while baseline levels of biomarkers of exposure were measured. Thereafter all subjects were randomly assigned to one of 5 groups: group A continued to smoke $\mathrm{CC}$, group B switched to another conventional cigarette (1 mg 'tar', FTC, CC2), groups C and D switched to EHCSS, and group E stopped smoking, for a period of eight days each. This study design included two EHCSS groups: one group (group C, EHCSS(CS)) smoked the EHCSS under controlled smoking conditions (maximum 30 cigarettes per day, smoking only allowed every 32 minutes from 7 a.m. to 11 p.m.) as previously described (13). The second group [group D, EHCSS(UCS)] smoked the EHCSS under uncontrolled conditions, up to a maximum of 60 cigarettes per day at any time between 7 a.m. and 11 p.m.. ETS measurements were conducted for the 5 groups during this eight day period in the following sequence: group E, C, D, $\mathrm{B}$, and $\mathrm{A}$.

\section{Study subjects}

50 male and 50 female adult smokers, mean age 34 years, mean body mass index (BMI) 24.6 were enrolled into the study and randomized. 98 subjects participated in the ETS measurements. 
Table 1. Concentrations of ETS markers from gravimetric measurement of air samples and chemical analysis [data from only one station are reported $(N=1)]$

\begin{tabular}{|c|c|c|c|c|c|}
\hline \multirow[b]{2}{*}{ Parameters investigated } & \multicolumn{5}{|c|}{ Study group } \\
\hline & CC1 & $\mathrm{CC} 2$ & $\begin{array}{l}\text { EHCSS } \\
\left(\mathrm{CS}^{\mathrm{a}}\right)\end{array}$ & $\begin{array}{l}\text { EHCSS } \\
\left(\text { UCS }^{\mathrm{b}}\right)\end{array}$ & No-smoking \\
\hline $\begin{array}{l}\text { Gravimetric respirable suspended } \\
\text { particulate matter RSP }\left(\mu \mathrm{g} / \mathrm{m}^{3}\right)\end{array}$ & 270.4 & 141.7 & 71.2 & 78.8 & 59.9 \\
\hline \multicolumn{6}{|c|}{ ETS markers $\left(\mu g / m^{3}\right)$} \\
\hline $\begin{array}{l}\text { Solanesol-related particulate matter } \\
\text { (Sol-PM) }\end{array}$ & 112.7 & 89.5 & $<3.0$ & 3.8 & $<3.0$ \\
\hline $\begin{array}{l}\text { Ultraviolet absorbing particulate matter } \\
\text { (UVPM) }\end{array}$ & 199.4 & 156.7 & 9.2 & 27.0 & 14.3 \\
\hline Fluorescing particulate matter (FPM) & 264.8 & 208.3 & 5.3 & 17.5 & 1.8 \\
\hline Nicotine & 12.5 & 14.9 & 0.9 & 0.7 & 0.6 \\
\hline 3-ethenylpyridine (3-EP) & 4.3 & 6.2 & $<0.3$ & $<0.3$ & $<0.3$ \\
\hline Cigarettes smoked & 18 & 18 & 18 & 46 & 0 \\
\hline Number of subjects & 20 & 20 & 19 & 19 & 20 \\
\hline
\end{tabular}

${ }^{\text {a }}$ Controlled smoking (max. 30 cig/day from 7 a.m. to 11 p.m. only every $32 \mathrm{~min}$ ).

${ }^{b}$ Uncontrolled smoking (max. 60 cig/day from 7 a.m. to 11 p.m. at any time).

\section{Test products}

The 'tar', nicotine and $\mathrm{CO}$ deliveries of the three cigarette products used in this study were determined from smoking machines operated under FTC conditions as follows: CC1 (Marlboro Lights ${ }^{\circledR}$ ): $11 \mathrm{mg}$ 'tar', $0.8 \mathrm{mg}$ nicotine and 12 mg CO; CC2 (Merit Ultima ${ }^{\circledR}$ ): $1 \mathrm{mg}$ 'tar', $0.1 \mathrm{mg}$ nicotine and $4 \mathrm{mg} \mathrm{CO}$; EHCSS (Accord ${ }^{\circledR} 2^{\text {nd }}$ generation): $3 \mathrm{mg}$ 'tar', $0.2 \mathrm{mg}$ nicotine and $0.7 \mathrm{mg} \mathrm{CO}$.

\section{ETS test room}

The ETS test room was a furnished and carpeted conference room. It had dimensions of $8.4 \mathrm{~m} \times 7.6 \mathrm{~m} \times 2.4 \mathrm{~m}$ (length $\times$ width $\times$ height), and a volume of $153 \mathrm{~m}^{3}$ and was ventilated by two mixed air supply air diffusers located in the ceiling. To ensure that the room air was well mixed during all measurement periods, two standmounted circulating fans $(0.6 \mathrm{~m}$ diameter $)$ placed on opposite sides of the room were continuously run at high speed. There were two air sampling stations in the room. Air sampling station I had its inlet air samplers located $3 \mathrm{~m}$ from the left wall and sampling station II $3 \mathrm{~m}$ from the right wall. The inlets of all instrument samplers were located approximately $1 \mathrm{~m}$ above the floor. Four smokers' chairs were placed in the center of the room approximately $1 \mathrm{~m}$ from the sampling stations. The remaining 16 subject chairs were placed in 3 rows further away from the sampling stations. The fresh air ventilation rate of the test room was maintained around $122 \mathrm{~L} / \mathrm{s}$ (2.9 air changes per hour) as measured each day according to the ASTM E741-95 method (14).

\section{Smoking regime}

In all cases, smoking took place over a period of one hour in the designated ETS test room. For the smoking groups $\mathrm{CC} 1, \mathrm{CC} 2$ and EHCSS(CS), each of the subjects was allowed to smoke only one cigarette any time during the one-hour period, if they so wished (no subject was required to smoke). For the smoking group EHCSS(UCS), each of the subjects was allowed to smoke as many cigarettes as they wished, but not exceeding the total of 60 cigarettes for the day. No more than four lit cigarettes were allowed at any one time during the experiments. The actual numbers of cigarettes consumed by these groups in the study are summarized in Table 1 . Twenty subjects of the no-smoking group were used as control. Under this smoking regime, smoking groups $\mathrm{CC} 1, \mathrm{CC} 2$ and EHCSS(CS) completed smoking by the 45 -minute mark of the one-hour period, whereas the EHCSS(UCS) group continued to smoke until the full hour was up. The timeline associated with the smoking and measurement activities of the study is illustrated in Figures 1,2 and 3.

\section{ETS measurement}

Air constituents: Concentration of RSP was measured in real time using a DustTrak ${ }^{\circledR}$ Aerosol Monitor model 8520 (TSI Inc, Shoreview, Minnesota), fitted with a cyclone separator for capturing particles $\leq 4 \mu \mathrm{m}$ in diameter. $\mathrm{CO}$ and TVOCs represented by the aldehyde group of compounds were also measured in real time, using an Innova 1312 Photoacoustic Multigas Monitor (California Analytical Instruments, Orange, California). Areas under the curve were calculated by use of the linear trapezoidal rule.

ETS markers: Particulate-phase RSP and vapor-phase samples were collected over two hours and analyzed for ETS markers. The sampling system and chemical analysis methods are described in JENKINS et al. (11). Using two separate constant-flow pumps housed in the same unit, particulate samples were collected using a polytetrafluoroethylene membrane filter at a flow rate of about 2.2 $\mathrm{L} / \mathrm{min}$; vapor-phase samples were collected using XAD-4 cartridges at a rate of about $1.1 \mathrm{~L} / \mathrm{min}$. Particulate-phase samples were analyzed for gravimetric RSP, Sol-PM, UVPM, and FPM. Vapor-phase samples were analyzed 

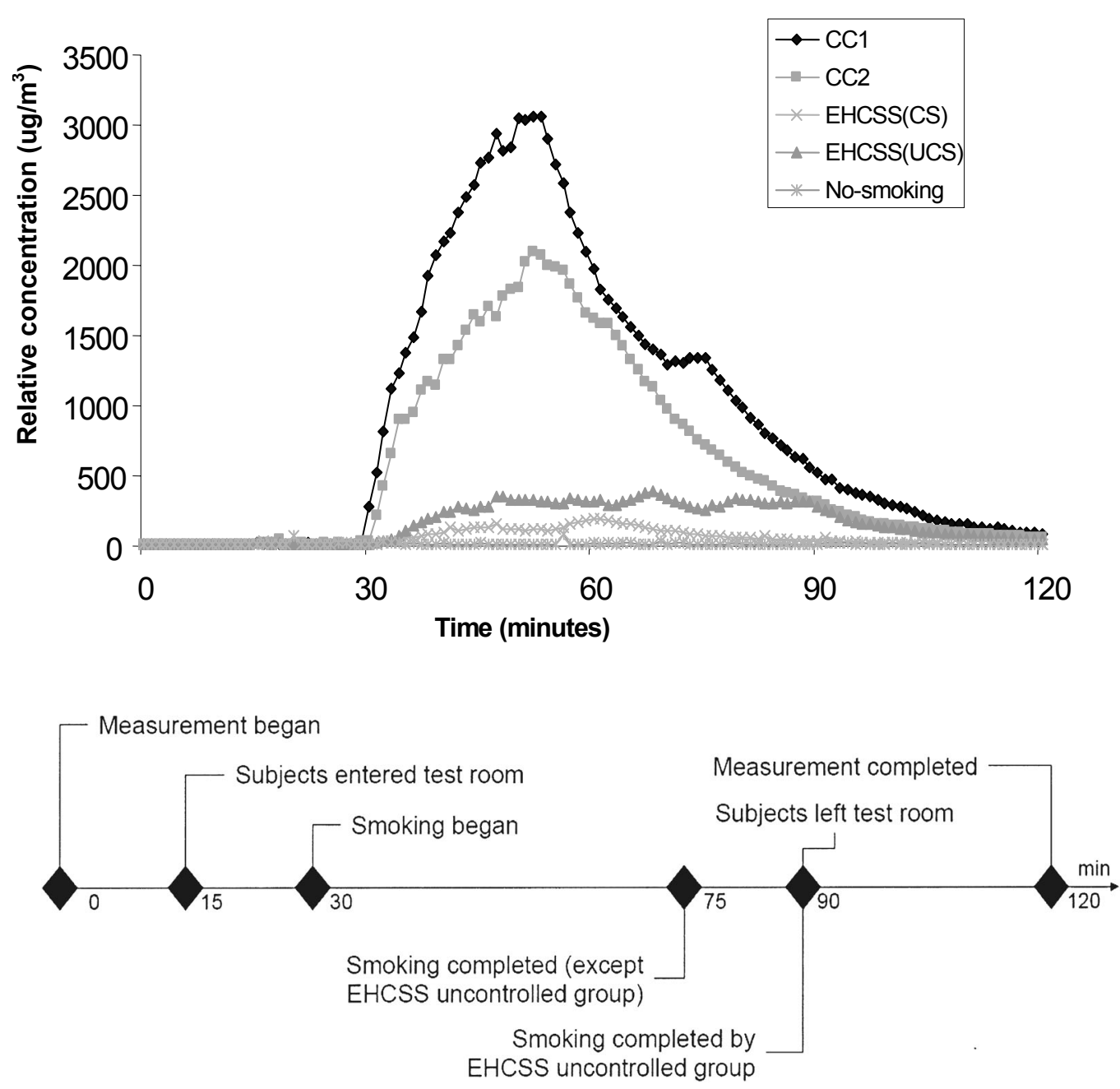

Figure 1. Relative real time respirable suspended particulate matter concentrations during various smoking conditions (note: instrument not calibrated with respect to ETS and hence does not provide absolute measures)

for nicotine and 3-EP. The ETS markers sampling systems and the chemical analysis used in this study were provided by Dr. R. A. Jenkins of Oak Ridge National Laboratory, Oak Ridge, Tennessee.

\section{RESULTS AND DISCUSSION}

The cigarette consumption during the 2-hour test period is shown in Table 1. The EHCSS(UCS) group smoked 2.6 times more cigarettes than the other smoking groups; this group also smoked more cigarettes towards the end of the one-hour smoking period compared with the beginning. In the controlled smoking groups (i.e. $\mathrm{CC} 1, \mathrm{CC} 2$ and EHCSS(CS)), smoking was usually completed 15 minutes before the end of the one-hour smoking period due to the limited number of cigarettes smoked. With no restriction of number of cigarettes smoked, smoking took place all the way up to the end of smoking period for the EHCSS(UCS) group.

Data from the two sampling stations were found to be similar, indicating that the room air was well mixed, so data from only one station are reported here. Concentra- tion versus time curves of RSP, CO and TVOCs are shown in Figures 1, 2 and 3.

As reported by JENKINS et al. (9), light-scattering based particle monitors such as the Dustrak ${ }^{\circledR}$ can over report measured values by as much as a factor of 4 unless complex calibration is carried out for the specific aerosols being measured. The Dustrak ${ }^{\circledR}$ monitor used for this study was calibrated at the manufacturer but did not undergo further calibration for ETS measurements since only real time relative changes from baseline were sought and quantitative measurements were provided by the gravimetric analysis in the study. Figure 1 illustrates the relative RSP concentrations over time during different smoking conditions but the individual values plotted should not be taken as absolute measures.

As illustrated in Figure 2, real time concentration of CO was below the limit of quantification (LOQ) of $0.2 \mathrm{ppm}$ in both EHCSS groups. Figure 3 illustrates that real time concentrations of TVOCs for the EHCSS(CS) group were at or just above the LOQ of $0.2 \mathrm{ppm}$ and were similar to concentration found in the no-smoking group. TVOC concentrations peaked at the end of the smoking period in the EHCSS(UCS) group (Figure 3) due to the larger 

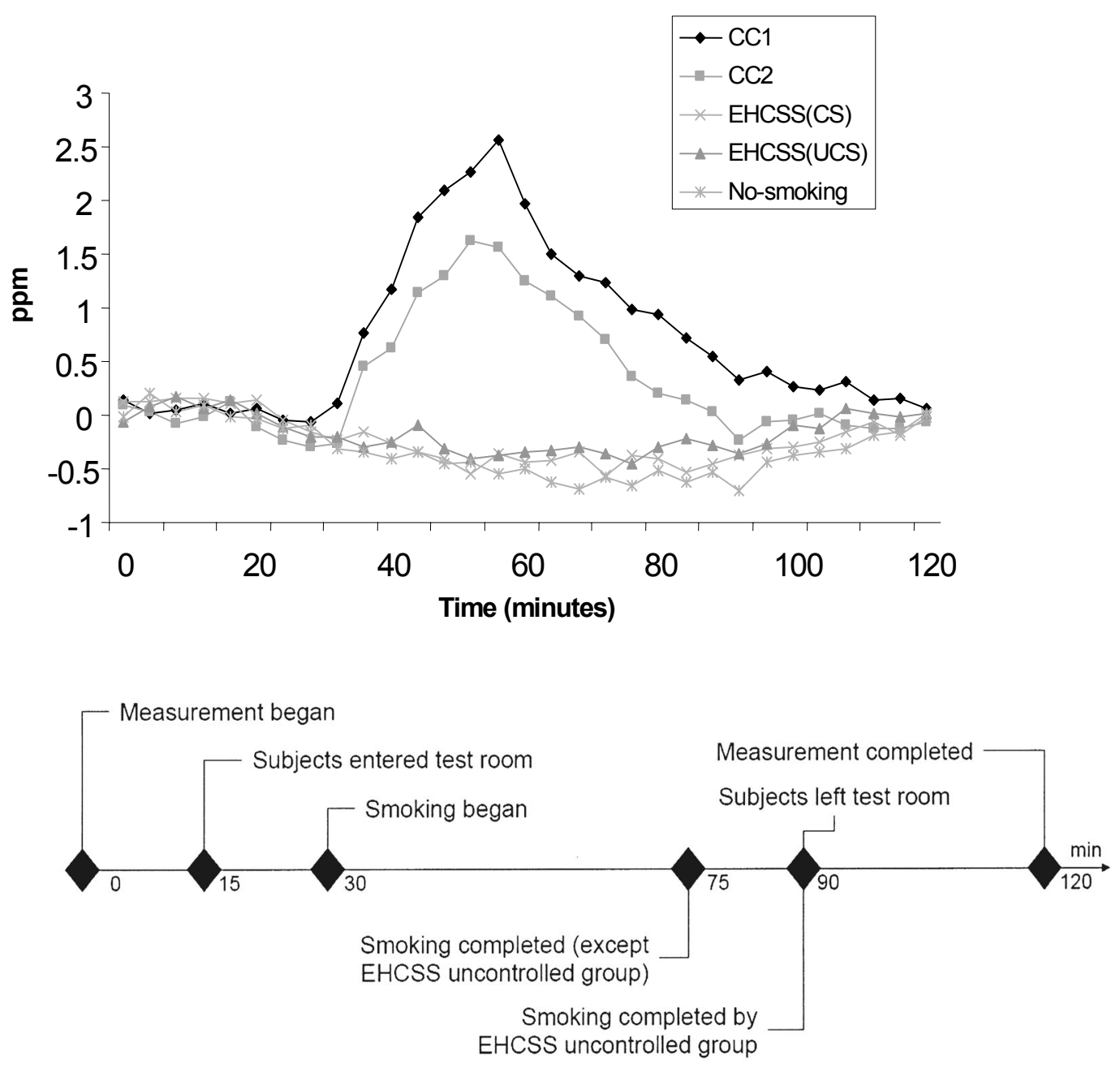

Figure 2. Real time $\mathrm{CO}$ concentrations during various smoking conditions

number of cigarettes smoked [46 cigarettes compared with 18 cigarettes for $\mathrm{CC} 1, \mathrm{CC} 2$ and EHCSS (CS)] and the continuance of smoking up to the end of the measurement period.

Table 1 summarizes results of the gravimetric and chemical analysis performed on particulate and vapor-phase samples collected. In general, a decrease in all ETS markers was observed in the EHCSS study groups compared with the conventional cigarette smoking groups $\mathrm{CC} 1$ and $\mathrm{CC} 2$.

Comparing with the $\mathrm{CC} 1$ group, a decrease in the gravimetric RSP concentration of $71-74 \%$ is observed in the EHCSS(CS) and EHCSS(UCS) groups, comparable to 78\% observed in the no-smoking group. Gravimetric RSP was about $50 \%$ lower in the $\mathrm{CC} 2$ group compared to the $\mathrm{CC} 1$ group.

Sol-PM concentration was not quantifiable in the EHCSS(CS) and the no-smoking groups, as the levels were below the limit of quantification $\left(<3 \mu \mathrm{g} / \mathrm{m}^{3}\right)$. In the EHCSS(UCS) group, a decrease of about $96 \%$ in Sol-PM concentration compared to either the $\mathrm{CC} 1$ or $\mathrm{CC} 2$ groups was observed. A decrease of 83-95\% in UVPM concentration was observed in EHCSS(CS) and EHCSS(UCS) groups when compared to the $\mathrm{CC} 1$ and $\mathrm{CC} 2$ groups. The decrease in FPM concentration observed was $92-98 \%$ in the EHCSS groups and the decrease in nicotine concentra- tion observed was 93-95\%. 3-EP concentration was not quantifiable in the EHCSS and the no-smoking groups. We selected tobacco specific markers of the particulate and the vapor phase of ETS. No sources of airborne solanesol have been reported; it is specific to tobacco combustion and regarded as probably the best marker for the particulate matter of ETS (15). UVPM and FPM have been shown to track the particulate phase of ETS well and have been used in many studies, both in personal ETS monitoring and in area sampling of ETS. Nicotine, due to its uniqueness in tobacco products, is often used as a marker for the vapor phase of ETS. However, it is prone to being adsorbed onto surfaces resulting in its determination being more variable than other ETS related compounds. 3-EP is regarded as a better marker for the vapor phase of ETS since it is adsorbed onto surfaces to a much smaller extent (16).

The real time measurements reported in this study are consistent with those in a previous study (7) where concentration of RSP from a study group involving EHCSS smoking was found to be about $90 \%$ lower than another study group involving conventional cigarette smoking. The current study improved on the previous one by including air sampling, gravimetric measurement and analysis of ETS markers in particulate and vapor phase. 

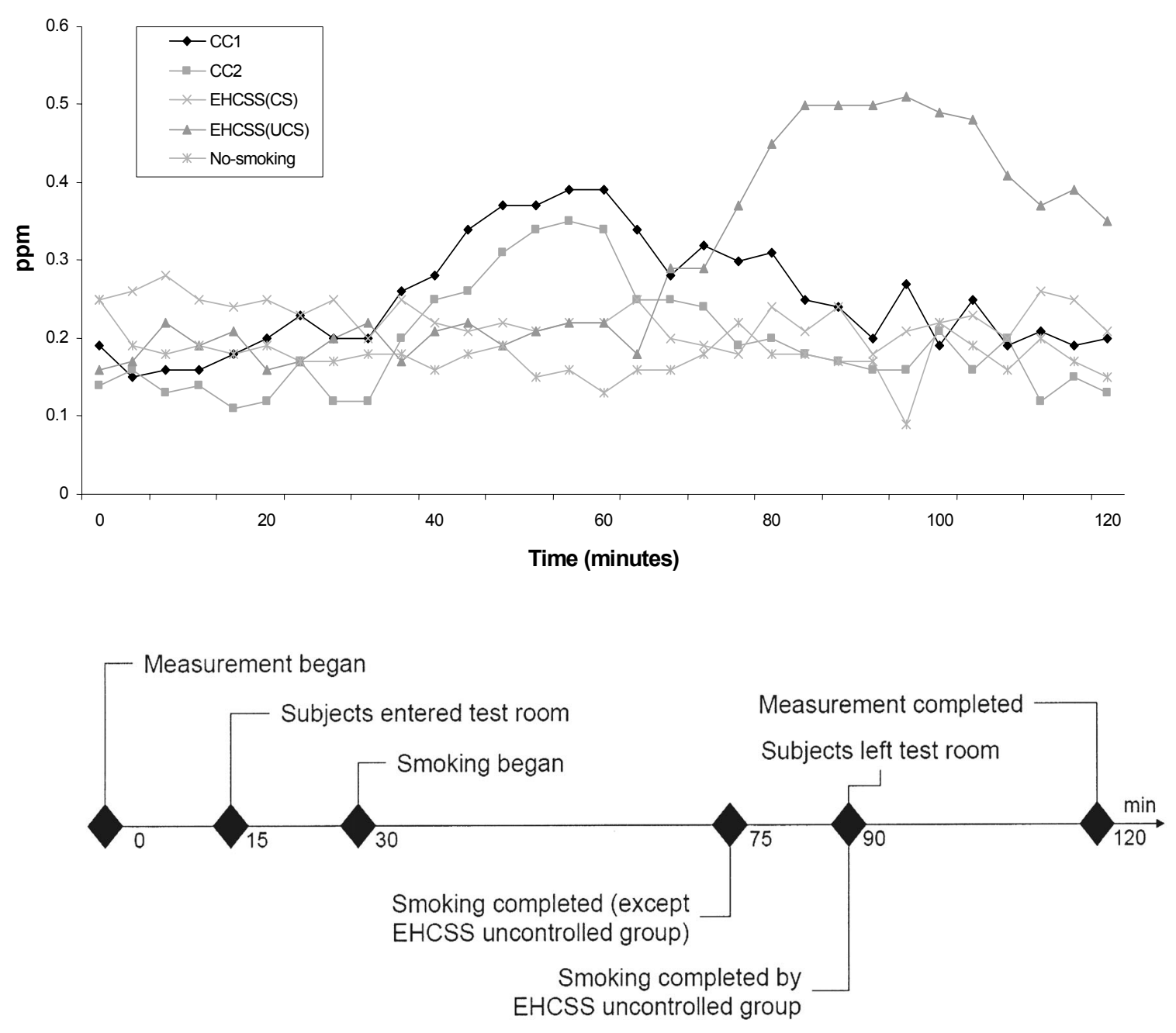

Figure 3. Real time total volatile organic compounds concentrations during various smoking conditions

A closer examination of the gravimetric and chemical analysis data would reveal that while measurements of the particulate-phase ETS markers such as UVPM and FPM were all derived from the gravimetric measurements of RSP, some reported concentrations of these markers were actually higher than that of gravimetric RSP. For example, in the CC2 group in Table 1, the average FPM was reported to be about $208 \mu \mathrm{g} / \mathrm{m}^{3}$ while the corresponding gravimetric RSP was only about $141 \mu \mathrm{g} / \mathrm{m}^{3}$. This apparent discrepancy is related to the use of a factor which converts fluorescence intensity as recorded by the instrument to FPM. This factor usually is derived as an average of 15 or so brands of cigarettes $(17,18)$. In the current study, the ETS was generated using a single type of cigarette in each of the study groups and the use of a general conversion factor is a limitation of the methodology. However, since the same methodology is applied to all the study groups, relative comparison of concentrations across the different study groups is still possible even though the concentrations of the ETS markers themselves should not be regarded as an absolute measure.

Using the same methodology, JENKINS et al. (17) reported measurements of ETS markers in smoking areas in a restaurant and single-room bars. Sol-PM ranged from 123 to $165 \mu \mathrm{g} / \mathrm{m}^{3}$, UVPM ranged from 95 to $146 \mu \mathrm{g} / \mathrm{m}^{3}, \mathrm{FPM}$ ranged from 133 to $155 \mu \mathrm{g} / \mathrm{m}^{3}$, nicotine ranged from 12 to $22 \mu \mathrm{g} / \mathrm{m}^{3}$ and 3-EP ranged from 2 to $5 \mu \mathrm{g} / \mathrm{m}^{3}$. These published values are in the same order of magnitude as those reported in Table 1 for the conventional cigarettes (CC1 and $\mathrm{CC} 2$ ), indicating that the concentrations of ETS markers reached in this study for those two groups are representative of conditions that might be encountered in real-life smoking environments.

\section{CONCLUSIONS}

Most of the measured air constituents and ETS markers measured in an indoor environment were substantially lower when adult smokers smoked the second generation Electrically Heated Cigarette Smoking System as compared to smoking conventional cigarettes, even when 2.6-fold more electrically heated cigarettes were smoked.

\section{REFERENCES}

1. International Agency for Research on Cancer: Monographs on the evaluation of carcinogenic risks to 
humans: Vol. 83, Tobacco smoke and involuntary smoking, WHO, IARC Press, Lyon, 2004.

2. Baker, R.R. and C. J. Proctor: The origins and properties of environmental tobacco smoke; Environ. Int. 16 (1990) 231-245.

3. U.S. Department of Health and Human Services: The health consequences of involuntary exposure to tobacco smoke; A report of the Surgeon General; U.S. Department of Health and Human Services, Centers for Disease Control and Prevention, Coordinating Center for Health Promotion, National Center for Chronic Disease Prevention and Health Promotion, Office on Smoking and Health, Rockville, MD, 2006.

4. Patskan, G. and W. Reininghaus: Toxicological evaluation of an electrically heated cigarette. Part 1: Overview of technical concepts and summary of findings; J. Appl. Toxicol. 23 (2003) 323-328.

5. Stabbert, R., P. Voncken, K. Rustemeier, H.J. Haussmann, E. Roemer, H. Schaffernicht, and G. Patskan: Toxicological evaluation of an electrically heated cigarette. Part 2: Chemical composition of mainstream smoke; J. Appl. Toxicol. 23 (2003) 329-339.

6. Roethig, H.J., R. Kinser, B. Nelson, and R.W. Lau: Investigations of biomarkers of exposure of adult smokers smoking electrically heated and conventional cigarettes; $8^{\text {th }}$ Annual Meeting Society for Research on Nicotine and Tobacco, Savannah, Georgia, February 20-23, 2002; RP0-55. Poster available at pmusascience.com. Accessed March 22, 2006.

7. Roethig, H.J., R.D. Kinser, R.W. Lau, R.A. Walk, and N. Wang: Short-term exposure evaluation of adult smokers switching from conventional to first-generation electrically heated cigarettes during controlled smoking; J. Clin. Pharmacol. 45 (2005) 133-145.

8. Gerstenberg B., W. Stinn, and W. Reininghaus: Comparison of environmental tobacco smoke from an electrically heated and a conventional cigarette; Poster presented at the $40^{\text {th }}$ Annual Meeting of the Society of Toxicology, San Francisco, CA March 25-29, 2001. The Toxicologist 60 (2001), (1-S) 431. Poster available at pmusa-science.com. Accessed March 22, 2006.

9. Jenkins, R.A., R.H. Ilgner, and B.A. Tomkins; Development and application of protocols for the determination of response of real-time particle monitors to common indoor aerosols; J. Air \& Waste Manage. Assoc. 54 (2004) 229-241.

10. Ogden, M.W., D.L. Heavner, T.L. Foster, K.C. Maiolo, S.L. Cash, J.D. Richardson, P. Martin, P.S. Simmons, F.W. Conrad, and P.R. Nelson: Personal monitoring system for measuring environmental tobacco smoke exposure; Environ. Technol. 17 (1996) 239-250.
11. Jenkins, R.A., M.P. Maskarinec, R.W. Counts, J.E. Caton, B.A. Tomkins, and R.H. Ilgner: Environmental tobacco smoke (ETS) in an unrestricted smoking workplace: area and personal exposure monitoring; J. Exposure Anal. Environ. Epidemiol. 11 (2001) 369-380.

12. Eudy, L.W., F.A. Thome, D.L. Heavner, C.R. Green, and B.J. Ingebrethesen: Studies on the vapor-particulate phase distribution of environmental nicotine by selected trapping and detection methods; Proceedings, $79^{\text {th }}$ Annual meeting of the Air Pollution Control Association, Paper 86-38.7, 1986.

13. Roethig, H.J., B.K. Zedler, R.D. Kinser, S. Feng, B.L. Nelson, and Q. Liang: Short-term clinical evaluation of a second-generation electrically heated cigarette smoking system; J. Clin. Pharmacol. 47 (2007) 518-530.

14. ASTM. Standard test method for determining air change in a single zone by means of a tracer gas; Method E741-95, American Society for Testing and Materials, Philadelphia, PA, 1995, pp. 171-186.

15. Tang, H., G. Richards, C.L. Benner, J.P. Tuominen, M.L. Lee, E.A. Lewis, L.D. Hansen, and D.J. Eatough: Solanesol: a tracer for environmental tobacco smoke particles; Environ. Sci. Technol. 24 (1990) 848-852.

16. Piade, J. J., S.D’Andres, and E.B. Sanders: Sorption phenomena of nicotine and ethenylpyridine vapours on different materials in a test chamber; Environ. Sci. Technol. 33 (1999) 2046-2052.

17. Jenkins, R.A., D. Finn, B.A. Tomkins, and M.P. Maskarinec: Environmental tobacco smoke in the nonsmoking section of a restaurant: A case study; Regulatory Toxicol. Pharmacol. 34 (2001) 213-220.

18. Jenkins, R.A., personal communication (2004).

Corresponding author:

Raymond W. Lau

Philip Morris USA Research Center

P.O. Box 26603, Richmond VA 23261

USA

Tel: (1) 8043352835

Fax: (1) 8043352090

E-mail: Raymond.W.Lau@pmusa.com 